\title{
Non-cystic fibrosis bronchiectasis
}

\author{
MP Smith \\ ${ }^{1}$ Specialist Registrar in Respiratory Medicine, Royal Infirmary of Edinburgh, Edinburgh, UK
}

\begin{abstract}
Bronchiectasis is a chronic debilitating condition. Pathologically, a vicious cycle of infection and inflammation exists in the permanently damaged airways with patients suffering a persistent cough, chronic daily sputum production and recurrent chest infections. Once termed an 'orphan disease', the prevalence of bronchiectasis has become increasingly recognised over the past few decades. The associated burden of disease in terms of respiratory morbidity, effect on patients' healthrelated quality of life and the economic cost of long term management is significant and it has become apparent that more research into its causes and management is urgently needed. This article reviews what is currently known about bronchiectasis, its pathophysiology, aetiology and management strategies.
\end{abstract}

Correspondence to MP Smith, Royal Infirmary of Edinburgh, 5 I Little France Crescent, Old Dalkeith Road, Edinburgh EHI 6 4SA, UK

tel. +44 (0) I3I 242 I92I e-mail maevemurray@hotmail.com

KEYWORDS Bronchiectasis, infection, exacerbations, management

DECLARATION OF INTERESTS No conflict of interests declared.

Originally described by René Laennec in 1819 , bronchiectasis is a chronic respiratory condition characterised by abnormal, permanently damaged and dilated bronchi.' Clinically, the disease is manifest by persistent or recurrent bronchial sepsis, the impact of which was perhaps best described by Warner in 1932 when he wrote of 'the copious foetid sputum... marked constitutional symptoms... making the patient a social outcast'. ${ }^{2}$ It is a debilitating illness responsible for significant morbidity, with patients typically suffering a persistent cough, chronic daily sputum expectoration, recurrent chest infections and a poor health-related quality of life.,4 The condition has a substantial socioeconomic cost because both primary and secondary healthcare resources are frequently used and periods of sick leave are common. ${ }^{5}$

Despite this, bronchiectasis has been a poorly studied disease that until recently had no national guidelines for management and the evidence base for many of its treatments relied on consensus expert opinions. ${ }^{6}$ The aim of this review article is to explore what is currently known in non-cystic fibrosis bronchiectasis, including its causes, diagnosis and management as well as future areas of research.

\section{PREVALENCE AND BURDEN}

Population studies in bronchiectasis are limited. Although it is widely believed that there has been an overall decline in incidence (due to more effective treatment of childhood respiratory conditions, successful vaccination programmes and strategies for the control of pulmonary tuberculosis), it remains an important problem. There is still a high incidence in developing countries and globally with the increased life expectancy of the general population, there is a greater risk of more people developing chronic illness, including bronchiectasis. ${ }^{7,8}$

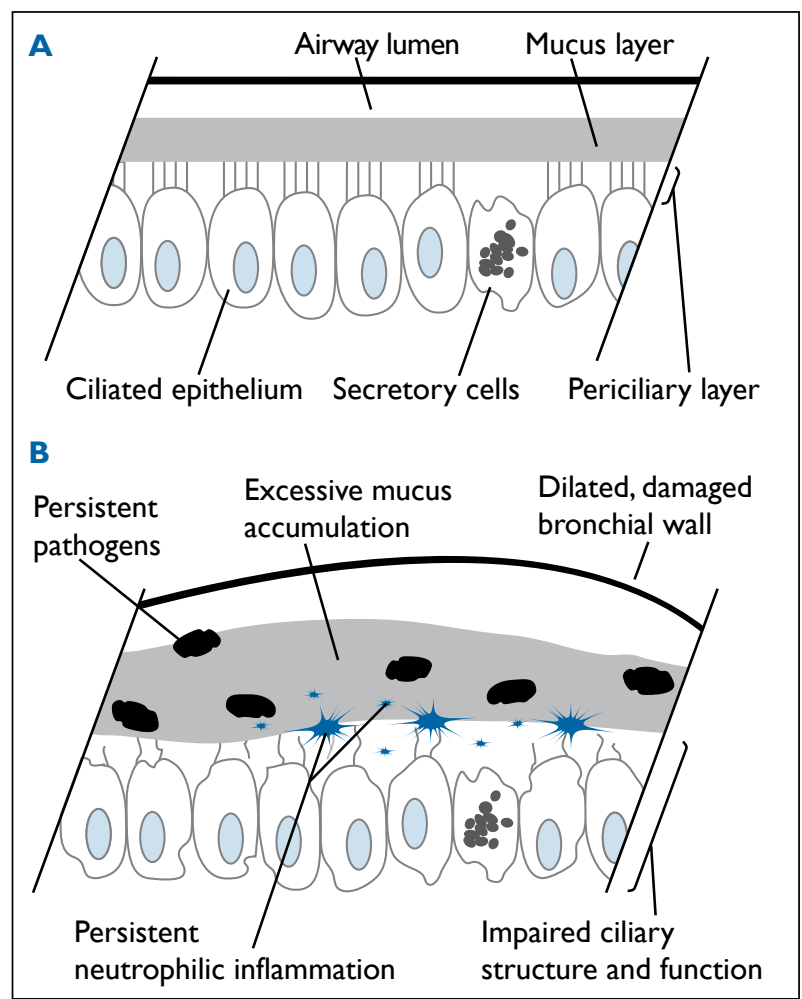

FIGURE I A:The normal mucociliary clearance mechanism. B:Abnormal mucociliary clearance mechanism in the bronchiectatic airway.

A retrospective cohort study of health claims between 1999-2001 in the US suggested the prevalence of bronchiectasis to be 4.2 per 100,000 population aged 18-34 years and 271.8 per 100,000 population aged $>75$ years. ${ }^{9}$ Clinical studies reflect such increased prevalence in the older population and have also observed an overall increased prevalence among females, with figures varying between $63 \%$ and $68 \%$, perhaps due to both biological and sociological factors. ${ }^{9-12}$ 




FIGURE 2 The vicious cycle in bronchiectasis. ${ }^{17}$

Morbidity in bronchiectasis is often quantified in terms of frequency of infective exacerbations as this perhaps has greatest impact both socioeconomically and individually on patients' health-related quality of life. US data for 1993-2006 found the average annual prevalence of hospitalisation due to bronchiectasis to be 16.5 per 100,000 population. ${ }^{13}$ UK hospital admission data for 2007-08 found bronchiectasis to be the primary diagnosis in one in 1,800 hospitalisations and bronchiectasis-related deaths in England and Wales have shown a rise in absolute numbers of deaths per year from 797 in 2001 to 908 in 2007 , an increase in mortality of $3 \%$ per annum. ${ }^{14}$

\section{PATHOPHYSIOLOGY}

In bronchiectasis, the airways are permanently inflamed, damaged and dilated and the usual mucociliary clearance defence mechanism is impaired (Figure la and Ib). With impaired host defences, the lungs are vulnerable to pathogens and the airways become chronically infected with a variety of bacteria which promotes further neutrophilic inflammation. The bacterial density in the airways has been shown to correlate with the degree of airways inflammation; with increasing bacterial load, there is an exaggerated inflammatory response with greater numbers of neutrophils and higher concentrations of neutrophil degradation products and other inflammatory markers. ${ }^{15,16}$ A vicious cycle of infection and inflammation develops with persistent symptoms, frequent exacerbations and further airways damage (Figure 2). ${ }^{17}$

Studies have found that $64-79 \%$ of patients with bronchiectasis are chronically infected with pathogenic bacteria in their airways even when apparently clinically stable. ${ }^{18-20}$ The most common infecting pathogens are Haemophilus influenzae (47-55\%) and Pseudomonas aeruginosa (12-26\%). Other pathogens frequently responsible for chronic infection include Moraxella catarrhalis, Streptococcus pneumoniae and Staphylococcus aureus. Longitudinal data are limited, but in a five-year follow-up study, $74 \%$ of patients remained chronically infected with the same organism responsible in more than half..$^{18}$
TABLE I Clinical, microbiological and radiological features used to assess disease severity

\begin{tabular}{|c|c|c|c|}
\hline \multirow[t]{2}{*}{ Characteristic } & \multicolumn{3}{|c|}{ Disease severity } \\
\hline & Mild & Moderate & Severe \\
\hline $\begin{array}{l}\text { Sputum } \\
\text { colour }\end{array}$ & Mucoid & Mucopurulent & Purulent \\
\hline $\begin{array}{l}24 \text { hr sputum } \\
\text { volume }\end{array}$ & $<5 \mathrm{ml}$ & & $\geq 25 \mathrm{ml}$ \\
\hline $\begin{array}{l}\text { Exacerbation } \\
\text { frequency }\end{array}$ & $\begin{array}{l}\leq 3 \text { per } \\
\text { annum }\end{array}$ & & Multiple \\
\hline $\begin{array}{l}\text { Exacerbation } \\
\text { severity }\end{array}$ & $\begin{array}{l}\text { Oral } \\
\text { antibiotics }\end{array}$ & & $\begin{array}{l}\text { Intravenous } \\
\text { antibiotics } \\
\text { and } \\
\text { adjunctive } \\
\text { measures }\end{array}$ \\
\hline $\begin{array}{l}\text { Sputum } \\
\text { bacteriology }\end{array}$ & $\begin{array}{l}\text { Not } \\
\text { chronically } \\
\text { infected }\end{array}$ & $\begin{array}{l}\text { Mixed flora } \\
\text { or various } \\
\text { pathogens (e.g. } \\
\text { H. influenzae, } \\
\text { M. catarrhalis, } \\
\text { S. pneumoniae, } \\
\text { S. aureus) }\end{array}$ & $\begin{array}{l}\text { Pseudo- } \\
\text { monas } \\
\text { aeruginosa }\end{array}$ \\
\hline $\begin{array}{l}\text { Affected } \\
\text { lobes on CT }\end{array}$ & One lobe & & All lobes \\
\hline $\begin{array}{l}\text { Degree of } \\
\text { bronchial } \\
\text { dilatation }\end{array}$ & $\begin{array}{l}\text { Tubular } \\
\text { dilatation }\end{array}$ & $\begin{array}{l}\text { Varicose } \\
\text { dilatation }\end{array}$ & $\begin{array}{l}\text { Cystic } \\
\text { dilatation }\end{array}$ \\
\hline
\end{tabular}

Non-tuberculous mycobacteria (NTM) may also be isolated from the sputum and such infection is recognised as a cause as well as a complication of bronchiectasis. A prospective study of 100 patients with bronchiectasis in 2005 found the prevalence of NTM to be $2 \%$, with I\% requiring treatment. ${ }^{21}$ A later study similarly found a prevalence of $9 \%$ (seven out of 80 patients), with only $2.5 \%$ requiring treatment. ${ }^{22}$ The actual prevalence of NTM infection in non-cystic fibrosis bronchiectasis needs further study.

\section{DIAGNOSIS}

The diagnosis of bronchiectasis initially relies on clinical suspicion. A persistent cough is present in more than $90 \%$ of patients and three-quarters describe daily sputum expectoration. ${ }^{3}$ Sputum is often discoloured with a yellow or green purulence, even when patients are clinically well and haemoptysis may be a feature. ${ }^{23}$ There is usually a history of recurrent chest infections and other respiratory symptoms related to airways obstruction (dyspnoea and wheeze) and mucus plugging (chest pain) may be described. ${ }^{3}$ Patients frequently suffer systemically with general malaise and fatigue which, together with the chronic respiratory symptoms, adversely affects health-related quality of life. ${ }^{4}$ Clinical signs in bronchiectasis may include finger clubbing (2-3\%), wheeze $(21-34 \%)$ and crackles $(69.9-73 \%)$, but typically physical examination is entirely normal. ${ }^{3}$ 
TABLE 2 Common causes of non-cystic fibrosis bronchiectasis, incidence and typical supporting diagnostic features. ${ }^{3,11,20}$

\begin{tabular}{|c|c|c|}
\hline AETIOLOGY & INCIDENCE & SUPPORTING DIAGNOSTIC FEATURES \\
\hline $\begin{array}{l}\text { Post infectious (e.g. pneumonia, } \\
\text { pertussis, Mycobacterium tuberculosis, } \\
\text { Nontuberculous mycobacteria) }\end{array}$ & $29-42 \%$ & - History or radiological evidence of previous infection \\
\hline $\begin{array}{l}\text { Connective tissue disease } \\
\text { (commonly rheumatoid arthritis; } \\
\text { also systemic sclerosis, systemic } \\
\text { lupus erythematosis, relapsing } \\
\text { polyarthritis, ankylosing spondylitis) }\end{array}$ & $3-6 \%$ & $\begin{array}{l}\text { - History or clinical signs of connective tissue disease } \pm \text { vasculitis } \\
\text { - Positive findings on autoimmune screen (e.g. rheumatoid factor, anti-nuclear } \\
\text { antibodies, antineutrophil cytoplasmic antibodies) }\end{array}$ \\
\hline $\begin{array}{l}\text { Allergic bronchopulmonary } \\
\text { aspergillosis }\end{array}$ & $\mathrm{I}-8 \%$ & $\begin{array}{l}\text { - History of asthma } \\
\text { - Peripheral eosinophilia } \\
\text { - } \uparrow \text { Total serum Immunoglobulin (Ig) E } \\
\text { - } \uparrow \text { Specific IgE and lgG to Aspergillus fumigatus } \\
\text { - Positive skin test reactivity to Aspergillus fumigatus } \\
\text { - Central bronchiectasis on CTchest scan }\end{array}$ \\
\hline $\begin{array}{l}\text { Immunodeficiency } \\
\text { (typically common variable } \\
\text { immunodeficiency, X-linked } \\
\text { agammaglobulinaemia, IgA } \\
\text { deficiency) }\end{array}$ & $\mathrm{I}-8 \%$ & $\begin{array}{l}\text { - Variable deficiencies possible [IgG (including IgG subclasses),lgA, lgM] } \\
\text { - In IgG subclass } 2 \text { deficiency, history of recurrent infections with gram+ve } \\
\text { encapsulated organisms } \\
\text { - Low baseline specific antibody levels against tetanus toxoid and the } \\
\text { polysaccharide capsules of Streptococcus pneumoniae and Haemophilus } \\
\text { influenzae type B }\end{array}$ \\
\hline Cystic fibrosis & $1-4 \%$ & $\begin{array}{l}\text { - Symptoms of malabsorption, male infertility } \\
\text { - Upper lobe bronchiectasis on CT chest scan } \\
\text { - Persistent culture of Staphylococcus aureus in sputum } \\
\text { - Positive cytogenetics for cystic fibrosis transmembrane regulator } \\
\text { receptor mutations } \\
\text { - Positive sweat test }\end{array}$ \\
\hline $\begin{array}{l}\text { Ciliary defect } \\
\text { (e.g. primary ciliary dyskinesia) }\end{array}$ & $1-10 \%$ & $\begin{array}{l}\text { - History of chronic upper respiratory tract problems, otitis media, male } \\
\text { infertility } \\
\text { - Positive saccharin taste test (saccharin not tasted after } 60 \text { minutes) } \\
\text { - Abnormal ciliary beat pattern } \pm \text { frequency on nasal brushings }\end{array}$ \\
\hline $\begin{array}{l}\text { Inflammatory bowel disease } \\
\text { (ulcerative colitis, Crohn's disease) }\end{array}$ & $1-3 \%$ & $\begin{array}{l}\text { - History or clinical signs } \\
\text { - Positive pathological features on colonoscopy }\end{array}$ \\
\hline $\begin{array}{l}\text { Aspiration/inhalation of } \\
\text { foreign body }\end{array}$ & $1-4 \%$ & $\begin{array}{l}\text { - History of aspiration } \\
\text { - Localised (single lobe) bronchiectasis } \\
\text { - Positive findings at bronchoscopy }\end{array}$ \\
\hline Idiopathic & $26-53 \%$ & - Above causes excluded \\
\hline
\end{tabular}

The diagnosis of bronchiectasis is confirmed radiologically using computed tomography (CT) of the chest. The CT characteristics were first described by Naidich in 1982, with the defining diagnostic feature being bronchial dilatation; the internal diameter of the bronchial lumen is greater than that of the adjacent artery. ${ }^{24}$ The degree of dilatation is typically categorised as tubular, varicose or cystic. Other specific signs supporting the diagnosis include air-fluid levels in the dilated bronchi, a peripheral distribution of dilated bronchi, clusters of cysts and bronchial wall thickening. Emphysema and a mosaic attenuation pattern due to small airways disease may also be seen.

After the initial diagnosis of bronchiectasis, disease severity should be assessed to help guide future management. Clinical, radiological and microbiological features are used to provide a quantitative assessment and should be evaluated when the patient is clinically stable (Table I).

\section{AETIOLOGY}

Bronchiectasis may be present as an independent entity or it may be an association of another disease process. Identifying a causative factor may have both therapeutic and prognostic implications, with previous studies finding that patient management altered in up to $50 \%$ in whom a specific aetiology had been diagnosed. ${ }^{11,20}$ Other studies have found that the presence of bronchiectasis can independently affect both morbidity and mortality of the associated underlying disease. ${ }^{25-27}$ A systematic investigation for causative factors or associated diseases is therefore crucial.

Aetiologies for bronchiectasis include: post-infective; aspiration/inhalation injuries to the airways; immunological, including both impaired immune defences and exaggerated immune responses; congenital syndromes; genetic diseases; systemic diseases and pulmonary diseases. Studies to date have published variable rates of 
identifiable aetiologies, with no cause found in up to $50 \%$ of patients. ${ }^{5,11,20}$ The rate of aetiological diagnosis varies perhaps due to differences in criteria for investigations as well as the population being studied - a higher proportion of post-infective bronchiectasis as an identifiable cause may be seen in lower socioeconomic countries where undertreated infection or rate of tuberculous infection for example is greater. ${ }^{28}$ However, there are clearly defined causes or risk factors for bronchiectasis either as a single disease entity or as part of a syndrome that require exploration. Table 2 gives the typical incidence of these causes and associations of bronchiectasis with their supporting diagnostic features.

\section{MANAGEMENT}

The aims of management of bronchiectasis are to reduce symptoms (particularly sputum volume, sputum purulence, cough and dyspnoea), reduce exacerbation frequency and severity, preserve lung function and improve health-related quality of life. Current strategies include medical management such as patient education, advice on airway clearance techniques, consideration of long-term treatments such as anti-inflammatory and antibacterial treatments, as well as optimal management of exacerbations. Surgery also remains a treatment option, as discussed below.

\section{Education}

Patients should understand the diagnosis of bronchiectasis and the importance of limiting further injury to the airways. Smoking is destructive to the integrity of the already damaged airway walls, and an independent risk factor for mortality. ${ }^{29,30}$ All patients should be advised to stop smoking. Limiting infective insults to the airways through prompt management of exacerbations is important and patients should be educated to recognise any deterioration in their symptoms and know to seek help. Prevention of viral insults by receiving the annual seasonal influenza vaccination is advised and, although a recent Cochrane review found only limited evidence to support the routine use of the 23 -valent pneumococcal vaccine, current UK guidelines recommend patients receive it. ${ }^{6,31}$

\section{Airway clearance}

The aim of chest physiotherapy is to improve airway clearance by mobilising secretions, enhancing effective expectoration and providing control of cough. Efficacy of regular chest physiotherapy in bronchiectasis has been proven in a randomised crossover trial which showed that twice-daily physiotherapy significantly improved perceived cough severity, 24-hour sputum volume yield, exercise capacity and health-related quality of life. ${ }^{32}$

Different physiotherapy techniques include postural drainage, autogenic drainage, the active cycle of breathing technique (ACBT), positive expiratory pressure (PEP), oscillatory PEP devices and high-frequency chest wall percussion. A UK survey of routine practice in 2002 found the most commonly practised techniques to be ACBT and postural drainage. ${ }^{33}$ Previous small studies in non-cystic fibrosis bronchiectasis have compared various techniques and found no single method to be superior, although patient preference for technique has varied. ${ }^{34,35}$ Acceptability of a technique is critical for regular compliance and as such all patients should be reviewed by a chest physiotherapist and instructed in a technique guided by individual preference.

Several other methods of airway clearance have been proposed either as independent treatments or more frequently as adjunctive measures to physiotherapy including humidification, inhaled hyperosmolar agents (nebulised hypertonic saline, inhaled mannitol), inhaled mucolytics [recombinant human DNase (rhDNase)] and anti-inflammatory therapies (inhaled corticosteroids and macrolides).

\section{Airways humidification}

Humidification aims to reduce mucus viscosity and enhance flow through the airways with small studies of short duration demonstrating increased airways clearance and sputum yield, but currently the evidence is insufficient to recommend it for routine use in bronchiectasis. ${ }^{36,37}$

Inhaled hyperosmolar agents: nebulised hypertonic saline and inhaled mannitol

Nebulised hypertonic saline may improve mucus transportability by altering the concentration of water in the mucus. ${ }^{38}$ Clinical trials are limited and although nebulised hypertonic $7 \%$ saline has been shown to yield greater sputum weights, with greater ease and less viscosity, larger and longer-term studies are needed. ${ }^{39}$

Mannitol acts as an osmotic agent in the airways and has been shown to enhance mucociliary clearance with improved mucus clearance for up to 24 hours after inhalation. ${ }^{40,41}$ Results from an open-label clinical study have been promising with improvements seen in small airways function, cough transportability and health-related quality of life and the outcome of a current long-term multicentre randomised controlled trial is eagerly anticipated. ${ }^{42}$

\section{Inhaled mucolytics (rhDNase)}

Excessive neutrophil activity causes release and accumulation of excessive quantities of DNA in the airway mucus. Inhalation of rhDNase cleaves the DNA, reducing sputum viscosity, improving expectoration, airway clearance and lung function. However, its routine use in bronchiectasis is not advised as it has been shown to have a significant negative effect on forced expiratory volume in one second $\left(F E V_{1}\right)$ and is associated with a higher rate of exacerbations, increased use of antibiotics and a greater rate of hospitalisations. ${ }^{43}$ 


\section{Inhaled corticosteroids}

The role of long-term inhaled corticosteroids has yet to be established, but the aim is to reduce inflammatory cell recruitment and activity in the airways thus limiting bronchial wall damage. ${ }^{44}$ To date, randomised controlled studies have shown regular high-dose inhaled corticosteroids (fluticasone $500 \mu \mathrm{\mu g}$ twice daily, or beclomethasone $750 \mu \mathrm{g}$ twice daily) reduce 24-hour sputum volume and improve health-related quality of life, but have no impact on $\mathrm{FEV}_{\text {, }}$ or exacerbation frequency. ${ }^{45-47}$ The optimal dose requires further clarification and at present the current evidence is insufficient to support the routine prescription of inhaled corticosteroids in bronchiectasis, but a sixmonth trial may be warranted for patients with severe disease or evidence of airways obstruction.

\section{Macrolides}

Macrolides were originally discovered as antibacterials but also have important immunomodulatory properties, although to date there have been few studies in bronchiectasis. The first clinical study was a randomised double-blind placebo-controlled trial of twice daily erythromycin for eight weeks. ${ }^{48}$ This showed a significant improvement in spirometry and reduction in 24-hour sputum volume. Two open-label studies of azithromycin have shown a reduction in exacerbation frequency. ${ }^{49,50}$ The most recent study was an uncontrolled study of once daily $250 \mathrm{mg}$ erythromycin; the authors observed that with 12 months' treatment patients experienced $50 \%$ fewer exacerbations than in the 12 months preceding the study and that the number of days of antibiotic use per year was also significantly reduced. ${ }^{51}$

The regular long-term use of macrolides is associated with potential adverse effects, including, perhaps most importantly, macrolide resistance which may be of particular significance in bronchiectasis complicated by NTM infection where macrolides have an important therapeutic role if treatment is required. However, their potential immunomodulatory and antibacterial effects are intriguing and potentially offer a real long-term therapeutic option in bronchiectasis, although further studies are needed.

\section{Long-term antibiotics}

The rationale for prescribing long-term antibiotics (oral or nebulised) in clinically stable bronchiectasis is to reduce the bacterial burden in the airways, therefore limiting inflammation and promoting healing of the bronchial tree. Disrupting the vicious cycle of infection and inflammation should reduce daily symptoms and exacerbation frequency. The evidence for long-term antibiotics is, however, limited. Studies have been conducted using both oral and nebulised antibiotics, but the study designs have varied using different criteria for selecting patients, different durations and doses of antibiotics as well as various outcome measures to assess response, making comparisons between regimens difficult and limiting their clinical application.

\section{Oral antibiotics}

The first randomised controlled trial of long-term oral antibiotic therapy was conducted by the Medical Research Council in 1957 and found that $2 \mathrm{~g}$ oral tetracycline given daily for 12 months significantly improved sputum volume and purulence and reduced the number of absent days from work due to respiratory ill health. ${ }^{52} \mathrm{~A}$ later randomised controlled trial of highdose amoxicillin ( $3 \mathrm{~g}$ twice daily) taken over eight months found that with treatment there was an improvement in symptoms, a reduction in 24-hour sputum volume and purulence, as well as fewer absent days from work..$^{53}$ There was no effect on exacerbation frequency, although exacerbations were less severe.

Other smaller, non-randomised studies of shorter duration have demonstrated similar benefits of regular oral antibiotic usage, as well as improved sputum bacterial clearance. Tolerance of long-term oral antibiotics is a clear factor that may affect compliance and was recognised early on in antibiotic studies. ${ }^{54}$ Aerosolised antibiotics began to be formally studied as potential means of delivering long-term antibacterial therapy to the diseased airways in the 1980s. With direct delivery to the lungs, systemic absorption could be anticipated to be minimal, with a lower risk of adverse systemic effects. ${ }^{55}$

\section{Nebulised antibiotics}

Nebulised antibiotics offer a targeted therapy with limited systemic side effects, but are expensive and may be less well tolerated due to bronchospasm - even with adjunctive treatment with a $\beta_{2}$ agonist. Until recently, the randomised controlled trials of long-term nebulised antibiotics have included only patients chronically colonised with $P$. aeruginosa. Twice-daily nebulised tobramycin in such patients has been shown to reduce sputum bacterial density but may also induce bronchospasm in a small number. ${ }^{56,57}$ The most recent randomised controlled trial of long-term nebulised antibiotics evaluated the impact of twice daily nebulised gentamicin over 12 months in patients chronically infected with a variety of pathogens. ${ }^{58}$ With treatment, there was a significant reduction in sputum bacterial density and airways inflammation, with less sputum purulence. Patients had greater exercise capacity, fewer exacerbations and an improved health-related quality of life, although the study concluded that treatment needed to be continuous for ongoing efficacy.

National guidelines recommend that patients suffering three or more exacerbations per year or those with fewer exacerbations, but significant morbidity should be considered for long-term antibiotics. ${ }^{6}$ Further studies are needed to define who would benefit from long-term antibiotics and the optimum mode and type of treatment. 


\section{Surgery}

Before the introduction of antibiotic therapy, the most effective management of bronchiectasis was surgery "the only means of "curing" bronchiectasis in the sense of causing the disappearance of the dilated bronchi is by surgical removal'. Currently, surgical management is reserved for specific indications, including major haemoptysis or localised disease causing significant morbidity not responsive to medical management. Retrospective case reviews have reported good outcomes, with low mortality rates $(<1 \%)$ and over twothirds of patients being symptom free at follow-up over four years. ${ }^{59}$ However, to date there have been no randomised controlled trials of surgical and nonsurgical management of bronchiectasis and in current practice referral for surgery is not common.

\section{Management of exacerbations}

Exacerbations of bronchiectasis are typically defined as a persistent ( $>24$ hours) deterioration in respiratory symptoms (increased cough, increased sputum volume, increased sputum purulence, breathlessness or wheeze) with or without systemic disturbance. They are responsible for significant patient morbidity, have a substantial socioeconomic cost and are a risk factor for mortality. ${ }^{5,14}$ Despite such consequences, there are no randomised placebo controlled trials evaluating the efficacy of antibiotic treatment of infective exacerbations and little evidence to guide selection of antibiotic(s), mode of delivery, duration of treatment or, indeed, the role of adjunctive therapies.

The current British Thoracic Society guideline recommends prompt antibiotic treatment for all patients presenting with an exacerbation. ${ }^{6}$ A sputum sample should be sent for microbiological culture at initial presentation, but this should not delay treatment commencing with an antibiotic choice made according to the patient's previous sputum microbiology history. Early studies have suggested that high doses of targeted antibiotic therapy are necessary in exacerbations of bronchiectasis and consensus expert opinion advises that all patients receive treatment for 14 days. ${ }^{60-62}$

Oral antibiotic therapy should be used as first-line management unless pathogenic organisms sensitive only to intravenous agents are cultured, or there is evidence of clinical sepsis necessitating acute inpatient admission, or if there has been no response to oral antimicrobials. Treatment with two antibiotics is recommended in patients colonised with $P$. aeruginosa or methicillinresistant $S$. aureus and in patients with multiple frequent exacerbations to prevent resistance emerging. Antibiotic choice for exacerbations should be guided by either local or national guidelines. ${ }^{6}$

\section{Adjunctive therapies in acute exacerbations}

Few studies have explored the role of adjunctive therapies in acute exacerbations of bronchiectasis. There is currently no evidence for efficacy of chest physiotherapy in acute exacerbations, but studies have compared different techniques and found no single method to be superior with no difference in the volume of sputum expectorated, spirometry or the perception of dyspnoea. ${ }^{63}$ The utility of other therapeutic strategies in acute exacerbations has not been studied; in particular, the use of corticosteroids (either systemic or inhaled), airway clearance techniques such as hypertonic nebulised saline, airways humidification and oxygen need further study.

\section{Assessing response to treatment}

Little is known about how best to assess the effect of treatment in exacerbations. Currently, evidence of a successful outcome is predominantly qualitative, relying on the patient's subjective assessment of symptom resolution. A recent prospective study of exacerbations requiring treatment with intravenous antibiotics identified 24-hour sputum volume, sputum bacterial clearance, C-reactive protein and the St George's Respiratory Questionnaire (a health-related quality of life questionnaire) to all be useful parameters in assessing treatment response. ${ }^{64,65}$ However, the latter is predominantly a research tool and impractical for use in routine clinical practice. Further studies are needed to identify and validate pertinent, easily accessible outcome measures for clinical use.

\section{MONITORING PATIENTS}

Routine follow-up in secondary care is recommended for all patients with features of severe disease (Table I), patients receiving long-term antibiotic treatment and for patients with bronchiectasis due to associated diseases where the presence of bronchiectasis is known to adversely affect prognosis. ${ }^{25}$ There should be regular monitoring of sputum bacteriology, lung function and assessment of treatment compliance. All patients should have a personalised plan for management of exacerbations that is updated regularly.

\section{CONCLUSION}

Bronchiectasis represents a significant disease entity that has been historically under-represented in medical research. Consequently the evidence base for its investigation and management is small and there is much that remains unknown. It has become increasingly recognised that treatments for bronchiectasis cannot be extrapolated from other chronic respiratory diseases and more studies are needed both to better understand disease pathogenesis and to establish the optimum approach to the management of this debilitating disease. 


\section{REFERENCES}

I Laennec R. A treatise in the diseases of the chest and on mediate auscultation. 4th ed. London: Longman; 1834.

2 Warner WP. Bronchiectasis: aetiology, diagnosis and treatment. Can Med Assoc J 1932; 27:583-93.

3 King PT, Holdsworth SR, Freezer NJ et al. Characterisation of the onset and presenting clinical features of adult bronchiectasis. Respir Med 2006; 100:2183-9. doi:10.1016/j.rmed.2006.03.012

4 Martínez-García MA, Perpiñá-Tordera M, Román-Sánchez $P$ et al. Quality-of-life determinants in patients with clinically stable bronchiectasis. Chest 2005; 128:739-45. doi:10.1378/ chest. 1 28.2.739

5 Kelly MG, Murphy S, Elborn JS. Bronchiectasis in secondary care: a comprehensive profile of a neglected disease. Eur J Intern Med 2003;14:488-92. doi:I0.10 I6/j.ejim.2003.10.002

6 Pasteur MC, Bilton D, Hill AT. British Thoracic Society guideline for non-CF bronchiectasis. Thorax 2010; 65(Suppl I):il-58. doi:10.1136/thx.2010.136119

7 Marostica PJ, Fischer GB. Non-cystic-fibrosis bronchiectasis: a perspective from South America. Paediatr Respir Rev 2006; 7:27580. doi:10.1016/j.prrv.2006.04.008

8 Babayigit $A$, Olmez $D$, Uzuner $N$ et al. A neglected problem of developing countries: noncystic fibrosis bronchiectasis. Ann Thorac Med 2009; 4:2I-4. doi: 10.4I03/I8I7-1737.4478I

9 Weycker D, Edelsberg J, Oster G et al. Prevalence and economic burden of bronchiectasis. Clin Pulm Med 2005; 12:205-9. doi:10.1097/0I.cpm.000017/422.98696.ed

10 Nicotra MB, Rivera M, Dale AM et al. Clinical, pathophysiologic, and microbiologic characterization of bronchiectasis in an aging cohort. Chest 1995; 108:955-6I. doi: 10.1378/chest. 108.4 .955

II Shoemark A, Ozerovitch L, Wilson R. Aetiology in adult patients with bronchiectasis. Respir Med 2007; 101:1 163-70. doi:10.1016/j. rmed.2006.1 1.008

12 Morrissey BM, Harper RW. Bronchiectasis: sex and gender considerations. Clin Chest Med 2004; 25:36I-72. doi:10.1016/j. $\mathrm{ccm}$.2004.01.011

13 Seitz AE, Olivier KN, Steiner CA et al. Trends and burden of bronchiectasis-associated hospitalizations in the United States, 1993-2006. Chest 2010; 138:944-9. doi:10.1378/chest. 10-0099

14 Roberts ME, Lowndes L, Milne DG et al. Socioeconomic deprivation, readmissions, mortality, and acute exacerbations of bronchiectasis. Intern Med J 20II; epub ahead of print 8 Feb. doi: I0.1 I I I/j. I 445-5994.20 I I.02444.x

15 Angrill J, Agustí C, de Celis R et al. Bronchial inflammation and colonization in patients with clinically stable bronchiectasis. Am J Respir Crit Care Med 200I; 164:1628-32.

16 Hill AT, Campbell EJ, Hill SL et al. Association between airway bacterial load and markers of airway inflammation in patients with stable chronic bronchitis. Am J Med 2000; 109:288-95. doi: 10.1016/ S0002-9343(00)00507-6

17 Cole PJ. Inflammation: a two-edged sword-the model of bronchiectasis. Eur J Respir Dis Suppl 1986;147:6-15.

18 King PT, Holdsworth SR, Freezer NJ et al. Microbiologic follow-up study in adult bronchiectasis. Respir Med 2007; 101:1633-8. doi:10.1016/j.rmed.2007.03.009

19 Angrill J, Agustí C, de Celis R et al. Bacterial colonisation in patients with bronchiectasis: microbiological pattern and risk factors. Thorax 2002; 57:15-9. doi:10.1 I36/thorax.57.1.15

20 Pasteur MC, Helliwell SM, Houghton SJ et al.An investigation into causative factors in patients with bronchiectasis. Am J Respir Crit Care Med 2000; $162(4 \mathrm{Pt} \mathrm{I})$ : 277-84.

2I Wickremasinghe M, Ozerovitch LJ, Davies G et al. Non-tuberculous mycobacteria in patients with bronchiectasis. Thorax 2005; 60:1045-51. doi:10.1136/thx.2005.046631

22 Fowler SJ, French J, Screaton NJ et al. Nontuberculous mycobacteria in bronchiectasis: prevalence and patient characteristics. Eur Respir J 2006; 28: | 204-I0. doi:I0.I |83/0903|936.06.00|49805
23 Murray MP, Pentland JL, Turnbull K et al. Sputum colour: a useful clinical tool in non-cystic fibrosis bronchiectasis. Eur Respir J 2009; 34:36 |-4. doi: I0.1 I83/0903 I936.00163208

24 Naidich DP, McCauley DI, Khouri NF et al. Computed tomography of bronchiectasis. J Comput Assist Tomogr 1982; 6:437-44. doi:10.1097/00004728-198206000-0000I

25 Swinson DR, Symmons D, Suresh $U$ et al. Decreased survival in patients with co-existent rheumatoid arthritis and bronchiectasis. $\mathrm{Br}$ J Rheumatol 1997; 36:689-91. doi:I0.1093/rheumatology/36.6.689

26 Patel IS, Vlahos I,Wilkinson TM et al. Bronchiectasis, exacerbation indices, and inflammation in chronic obstructive pulmonary disease. Am J Respir Crit Care Med 2004; 170:400-7. doi:10.1 164/ rccm.200305-648OC

27 Sumikawa $\mathrm{H}$, Johkoh T, Colby TV et al. Computed tomography findings in pathological usual interstitial pneumonia: relationship to survival. Am J Respir Crit Care Med 2008; 177:433-9. doi:10.1 164/ rccm.2006II-16960C

28 Kapur N, Karadag B. Differences and similarities in non-cystic fibrosis bronchiectasis between developing and affluent countries. Paediatr Respir Rev 2010; 12:91-6. doi:10.1016/j.prrv.2010.10.010

29 Finklea JD, Khan G, Thomas $S$ et al. Predictors of mortality in hospitalized patients with acute exacerbation of bronchiectasis. Respir Med 2010; 104:816-21. doi: 10.1016/j.rmed.2009.11.021

30 Verra $F$, Escudier E, Lebargy $F$ et al. Ciliary abnormalities in bronchial epithelium of smokers, ex-smokers, and nonsmokers. Am J Respir Crit Care Med 1995; I5I(3 Pt I):630-4.

3I Chang CC, Singleton RJ, Morris PS et al. Pneumococcal vaccines for children and adults with bronchiectasis. Cochrane Database Syst Rev 2009; 2:CD006316.

32 Murray MP, Pentland JL, Hill AT. A randomised crossover trial of chest physiotherapy in non-cystic fibrosis bronchiectasis. Eur Respir J 2009; 34: 1086-92. doi: 10.1 I83/09031936.00055509

33 O'Neill B, Bradley JM, McArdle $N$ et al. The current physiotherapy management of patients with bronchiectasis: a UK survey. Int J Clin Pract 2002; 56:34-5.

34 Eaton T, Young P, Zeng I et al. A randomized evaluation of the acute efficacy, acceptability and tolerability of flutter and active cycle of breathing with and without postural drainage in noncystic fibrosis bronchiectasis. Chron Respir Dis 2007; 4:23-30. doi: I0.1 I77/147997230607448 I

35 Thompson CS, Harrison S, Ashley J et al. Randomised crossover study of the Flutter device and the active cycle of breathing technique in non-cystic fibrosis bronchiectasis. Thorax 2002; 57:446-8. doi:10.1 I36/thorax.57.5.446

36 Conway JH, Fleming JS, Perring S et al. Humidification as an adjunct to chest physiotherapy in aiding tracheo-bronchial clearance in patients with bronchiectasis. Respir Med 1992; 86:109-14. doi:10.1016/S0954-6III (06)80225-8

37 Hasani A, Chapman TH, McCool D et al. Domiciliary humidification improves lung mucociliary clearance in patients with bronchiectasis. Chron Respir Dis 2008; 5:8I-6. doi: 10.1 I77/1479972307087/90

38 Shibuya Y, Wills PJ, Cole PJ. Effect of osmolality on mucociliary transportability and rheology of cystic fibrosis and bronchiectasis sputum. Respirology 2003; 8:18I-5. doi:10.1046/j.1440-1843. 2003.00454.x

39 Kellett F, Redfern J, Niven RM. Evaluation of nebulised hypertonic saline $(7 \%)$ as an adjunct to physiotherapy in patients with stable bronchiectasis. Respir Med 2005; 99:27-31. doi:10.1016/j. rmed.2004.05.006

40 Daviskas E, Anderson SD, Eberl S et al. Inhalation of dry powder mannitol improves clearance of mucus in patients with bronchiectasis. Am J Respir Crit Care Med 1999; 159:1843-8.

4I Daviskas E,Anderson SD, Eberl S et al.The 24-h effect of mannitol on the clearance of mucus in patients with bronchiectasis. Chest 2001; II9:414-2I. doi:I0.1378/chest. I 19.2.4I4

42 Daviskas E, Anderson SD, Gomes K et al. Inhaled mannitol for the treatment of mucociliary dysfunction in patients with bronchiectasis: effect on lung function, health status and sputum. Respirology 2005; I0:46-56. doi: I0. I I I I/j. I440-1843.2005.00659.x 
43 O'Donnell AE, Barker AF, llowite JS et al. Treatment of idiopathic bronchiectasis with aerosolized recombinant human DNase I. rhDNase Study Group. Chest 1998; II3:1329-34. doi:10.1378/ chest.I 13.5.1329

44 Gaga $M$, Bentley AM, Humbert $M$ et al. Increases in CD4+ T lymphocytes, macrophages, neutrophils and interleukin 8 positive cells in the airways of patients with bronchiectasis. Thorax 1998; 53:685-91. doi: 10.1136/thx.53.8.685

45 Tsang KW, Ho PL, Lam WK et al. Inhaled fluticasone reduces sputum inflammatory indices in severe bronchiectasis. Am J Respir Crit Care Med 1998; 158:723-7.

46 Tsang KW, Tan KC, Ho PL et al. Inhaled fluticasone in bronchiectasis: a 12 month study. Thorax 2005; 60:239-43. doi:10.1136/ thx.2002.003236

47 Elborn JS, Johnston B,Allen F et al. Inhaled steroids in patients with bronchiectasis. Respir Med 1992; 86:121-4. doi:10.1016/S09546III(06)80227-I

48 Tsang KW, Ho PI, Chan KN et al. A pilot study of low-dose erythromycin in bronchiectasis. Eur Respir J 1999; 13:36I-4. doi:10.1183/09031936.99.13236199

49 Davies G, Wilson R. Prophylactic antibiotic treatment of bronchiectasis with azithromycin. Thorax 2004; 59:540-I.

50 Cymbala AA, Edmonds LC, Bauer MA et al. The disease-modifying effects of twice-weekly oral azithromycin in patients with bronchiectasis. Treat Respir Med 2005; 4: I I7-22. doi:I0.2165/00I5I829200504020-00005

5 I Serisier DJ, Martin ML. Long-term, low-dose erythromycin in bronchiectasis subjects with frequent infective exacerbations. Respir Med 201 I; 105:946-9. doi:10.1016/j.rmed.201 1.01.009

52 Medical Research Council. Prolonged antibiotic treatment of severe bronchiectasis; a report by a subcommittee of the Antibiotics Clinical Trials (non-tuberculous) Committee of the Medical Research Council. Br Med J 1957; 2:255-9.

53 Currie DC, Garbett ND, Chan KL et al. Double-blind randomized study of prolonged higher-dose oral amoxycillin in purulent bronchiectasis. Q J Med 1990; 76:799-8I6.

54 Sobel S, Lichter EA, Davis JC et al. Adverse reactions to tetracycline, penicillin and an oleandomycin-penicillin mixture used in the long-term therapy of chronic pulmonary disease. Am J Med Sci 1962; 243:34I-53. doi:10.1097/0000044I-196203000-00009

55 Palmer LB, Smaldone GC, Simon SR et al. Aerosolized antibiotics in mechanically ventilated patients: delivery and response. Crit Care Med 1998; 26:3 I-9. doi:10.1097/00003246-199801000-000I3

56 Barker AF, Couch L, Fiel SB et al.Tobramycin solution for inhalation reduces sputum Pseudomonas aeruginosa density in bronchiectasis. Am J Respir Crit Care Med 2000; $162(2 \mathrm{Pt} \mathrm{I}): 48 \mathrm{I}-5$.

57 Drobnic ME, Sune P, Montoro JB et al. Inhaled tobramycin in noncystic fibrosis patients with bronchiectasis and chronic bronchial infection with Pseudomonas aeruginosa. Ann Pharmacother 2005; 39:39-44. doi: I0.1345/aph. IE099

58 Murray MP, Govan JR, Doherty Cl et al. A randomized controlled trial of nebulized gentamicin in non-cystic fibrosis bronchiectasis. Am J Respir Crit Care Med 201 I;183:49I-9. doi:I0.1 164/rccm.201005-0756OC

59 Bagheri R, Haghi SZ, Fattahi Masoum SH et al. Surgical management of bronchiectasis: analysis of 277 patients. Thorac Cardiovasc Surg 2010; 58:29|-4. doi:10.1055/s-0030-124994 I

60 Hill SL, Stockley RA. Effect of short and long term antibiotic response on lung function in bronchiectasis. Thorax 1986; 41:798800. doi:10.1136/thx.4I.10.798

6I Pines A, Raafat H, Plucinski K et al. Cephaloridine compared with penicillin and streptomycin in chronic purulent bronchitis. Controlled trials of increasing dosage of cephaloridine. $\mathrm{Br} J \mathrm{Dis}$ Chest 1967; 6I:I0I-10. doi:10.1016/S0007-097I(67)80033-0

62 Davies BI, Maesen FP, van Noord JA. Treatment of chronic and recurrent respiratory infections with intramuscular ceftazidime. J Antimicrob Chemother 1983; 12(Suppl A): I-8.

63 Patterson JE, Hewitt O, Kent $L$ et al. Acapella versus 'usual airway clearance' during acute exacerbation in bronchiectasis: a randomized crossover trial. Chron Respir Dis 2007; 4:67-74. doi: I0.1 I77/|479972306075483

64 Murray MP, Turnbull K, Macquarrie S et al. Assessing response to treatment of exacerbations of bronchiectasis in adults. Eur Respir J 2009; 33:3 12-7. doi: I0.I I83/09031936.00122508

65 Wilson CB, Jones PW, O'Leary CJ et al. Validation of the St. George's Respiratory Questionnaire in bronchiectasis. Am J Respir Crit Care Med 1997 Aug; I56(2 Pt I):536-4I.

\section{SELF-ASSESSMENT QUESTIONS}

I. In non-cystic fibrosis bronchiectasis, which ONE of the following organisms is most commonly cultured from sputum?

A. Bordetella pertussis

B. Haemophilus influenzae

C. Pseudomonas aeruginosa

D. Staphylococcus aureus

E. Streptococcus pneumoniae

2. Which ONE of the following features on a highresolution CT scan would be regarded as characteristic of bronchiectasis?

A. A mosaic pattern of attenuation.

B. Internal diameter of bronchi greater than internal diameter of adjacent pulmonary arteries.

C. Internal diameter of bronchi greater than internal diameter of adjacent bronchial arteries.

D. Consolidation in a peribronchial distribution.

E. Varicose thinning of bronchial walls.
3. Which ONE of the following is most accurate with regard to routine use of rhDNase in noncystic fibrosis bronchiectasis?

A. It has immunomodulatory as well as antimicrobial properties.

B. It has a beneficial effect on $\mathrm{FEV}$, when given intravenously.

C. It has a detrimental effect on FEV, when given intravenously.

D. It has a beneficial effect on FEV , when nebulised.

E. It has a detrimental effect on FEV, when nebulised.

4. Which ONE of these conditions is not classically associated with bronchiectasis?

A. Crohn's disease

B. Hypothyroidism

C. Non-tuberculous mycobacterial infection

D. Systemic sclerosis

E. X-linked agammaglobulinaemia

For the answers, please turn to page 190. 